\title{
Experimental and artificial neural network modeling study on soot formation in premixed hydrocarbon flames ${ }^{\text {is }}$
}

\author{
Fikret Inal $^{\mathrm{a}, *}$, Gokmen Tayfur ${ }^{\mathrm{b}}$, Tyler R. Melton ${ }^{\mathrm{c}}$, Selim M. Senkan ${ }^{\mathrm{c}}$ \\ ${ }^{a}$ Department of Chemical Engineering, Izmir Institute of Technology, Gulbahce Koyu-Urla, 35437 Izmir, Turkey \\ ${ }^{\mathrm{b}}$ Department of Civil and Environmental Engineering, Izmir Institute of Technology, Gulbahce Koyu-Urla, 35437 Izmir, Turkey \\ ${ }^{\mathrm{c}}$ Department of Chemical Engineering, University of California Los Angeles, Los Angeles, CA 90095, USA
}

Received 25 October 2002; revised 3 February 2003; accepted 7 February 2003; available online 17 March 2003

\begin{abstract}
The formation of soot in premixed flames of methane, ethane, propane, and butane was studied at three different equivalence ratios. Soot particle sizes, number densities, and volume fractions were determined using classical light scattering measurement techniques. The experimental data revealed that the soot properties were sensitive to the fuel type and combustion parameter equivalence ratio. Increase in equivalence ratio increased the amount of soot formed for each fuel. In addition, methane flames showed larger particle diameters at higher distances above the burner surface and propane, ethane, and butane flames came after the methane flames, respectively. Three-layer, feedforward type artificial neural networks having seven input neurons, one output neuron, and five hidden neurons for soot particle diameter predictions and seven hidden neurons for volume fraction predictions were used to model the soot properties. The network could not be trained and tested with sufficient accuracy to predict the number density due to a large data range and greater uncertainty in determination of this parameter. The number of complete data set used in the model was 156 . There was a good agreement between the experimental and predicted values, and neural networks performed better when predicting output parameters (i.e. soot particle diameters and volume fractions) within the limits of the training data.
\end{abstract}

(c) 2003 Elsevier Science Ltd. All rights reserved.

Keywords: Soot; Hydrocarbon flames; Artificial neural networks

\section{Introduction}

Particulate formation in combustion systems is a major concern due to their environmental and health effects. Soot is the product of incomplete combustion of hydrocarbon fuels and consists mainly of carbon $(\sim 90 \%)$. Carbon surfaces are known to be catalytic for the conversion of $\mathrm{SO}_{2}$ to $\mathrm{SO}_{4}^{-2}$, and $\mathrm{NO}$ to $\mathrm{NO}_{2}$ or $\mathrm{NO}_{3}^{-}$in the atmosphere [1].

Soot is one of the first recognized environmental carcinogens. The data in the literature suggest that there is a strong correlation between the concentrations of soot in the air and morbidity from bronchitis [2]. Soot also plays an important role in the development of various toxicological conditions in humans. Polycyclic aromatic hydrocarbons (PAH), the largest class of chemical carcinogens

\footnotetext{
* Corresponding author. Tel.: +90-232-498-6282; fax: +90-232-4986355.

E-mail address: fikretinal@iyte.edu.tr (F. Inal).

Published first on the web via Fuelfirst.com-http://www.fuelfirst.com
}

are mostly adsorbed to the particles at atmospheric conditions. Therefore, combustion emitted small soot particles provide a transport mechanism for adsorbed $\mathrm{PAH}$.

The formation and emission of soot from combustion processes have been studied extensively [3-6]. The amount of soot formed for a specific fuel depends on the type of flame and other physical parameters such as temperature and residence time. Baumgartner et al. [7] investigated the soot formation in atmospheric pressure, laminar, premixed hydrocarbon-air flames with the following fuels: acetylene, benzene, $n$-hexane, $n$-heptane, cyclohexane, cyclohexene, naphthalene, pyridine, thiophene, furan, and mixtures of ethylene with hydrogen. The various mixtures were tested for different $\mathrm{C} / \mathrm{O}$ ratios and flow velocities using a flat flame burner. Their experimental results imply that the general characteristics of soot formation, coagulation, and mass growth are similar for all the flames studied. They approximated the soot volume fraction growth by a first order expression with a temperature dependent rate 
constant. In addition, the amount of soot finally present varied with $\mathrm{C} / \mathrm{O}$ ratio and also depended on temperature above $1500 \mathrm{~K}$. Recently, Melton et al. [8,9] investigated the effects of equivalence ratio (i.e. (fuel/oxidizer) ratio divided by the stoichiometric (fuel/oxidizer) ratio) on the formation of PAH and soot in premixed methane/oxygen/argon and ethane/oxygen/argon flames. They determined the equivalence ratio dependencies of soot volume fraction and species mole fraction profiles using an empirical formula. Their experimental results showed that the sensitivity of soot volume fraction to equivalence ratio was about the same as those of aromatic species such as benzene, phenylacetylene, and naphthalene.

The detailed chemical kinetic mechanisms have been used extensively to model soot formation. These mechanisms include a large number of species in a large number of elementary reactions, and quality of predictions depends upon the quality and quantity of the thermochemical data of species and upon the kinetics and mechanisms of individual elementary reactions [10]. Frenklach et al. [11] investigated the relative sooting tendencies of 1,3-butadiene, benzene and ethylene for shock-tube pyrolysis conditions by a detailed kinetic model. It has been found that the fuel structure influences the soot formation by a change in the induction time and initial rate of soot formation for shocktube conditions. Recently, McEnally et al. [12] applied the simple Thermocouple Particle Densitometry technique to measure the absolute soot volume fractions in a several laminar non-premixed flames. Their method was based on the extraction of soot volume fraction from rapid insertion junction-temperature history of a thermocouple. Alternatively, Artificial Neural Network (ANN) approach has also been applied successfully for the prediction of pollutant emissions and other environmental problems. Hao et al. [13] used an ANN model to predict $\mathrm{NO}_{x}$ emission from a pulverized coal burned utility burner under various operating condition and coal quality. The ANN approach has also been applied to predict the atmospheric PAH emissions from a passenger car diesel engine as functions of fuel parameters (aromatic content, cetane index, gross heat power, nitrogen and sulphur content) and operating conditions (engine speed and torque) [14]. Diesel particulate emissions from the same engine have also been studied by Lucas et al. [15] using neural network modeling.

In this study, both experimental and ANN modeling techniques were used to investigate the soot formation in laminar, premixed, atmospheric pressure fuel/oxygen/argon flames. Four different hydrocarbon flames (methane, ethane, propane, and butane) at three different fuel-rich conditions (equivalence ratios of 2.4, 2.5, and 2.6) were studied.

\section{Experimental}

An illustration of the experimental system used is shown in Fig. 1. Atmospheric pressure, premixed, flat flames of fuel $/ \mathrm{O}_{2} / \mathrm{Ar}$ were stabilized over a $50 \mathrm{~mm}$ diameter porous, bronze burner. Ar was also used as a shield gas to protect the flames from surrounding air. The purities of the gases used in this study were $99.99 \%$ (Matheson, Rancho Cucamonga,

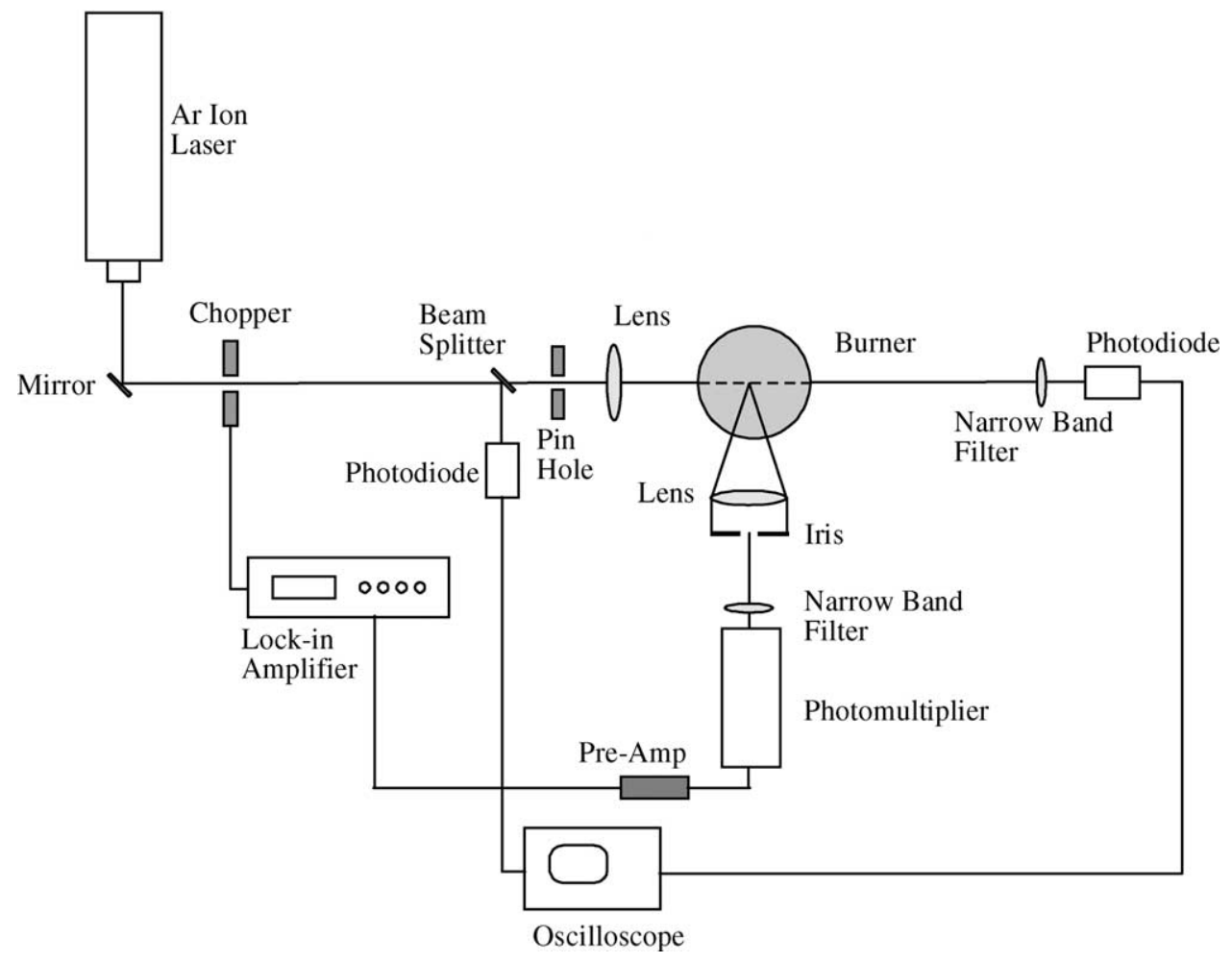

Fig. 1. Experimental setup. 
CA). The flow rates of reactant gases were controlled by calibrated mass flow controllers (Model 247C, MKS). The shield gas was regulated by a calibrated rotameter.

Soot particle diameters, number densities and volume fractions were determined using classical laser light scattering and extinction measurements [16]. The light source used was a tunable argon ion laser with $514.5 \mathrm{~nm}$ line and 1.0 W power (Spectra Physics, 2037). A photomultiplier tube (PMT) (Hamamatsu, R1463) was used to measure the relative intensity of that fraction of the incident light scattered at $90^{\circ}$ by the soot particles in the flame being investigated. The transmitted light was measured with a photodiode (Hamamatsu, 51336-BQ) and recorded with an oscilloscope. Two devices were used to obtain high signal to noise ratio. (1) Narrow band-pass filters were placed in front of the PMT and photodiode. (2) The incident laser light was chopped at a frequency of $1000 \mathrm{~Hz}$ and the PMT signal was read out with a lock-in amplifier (EG\&G 5205) which was synchronized with the chopper. The lock-in amplifier read out only that component of the PMT output pulsed with the same frequency and phase as the chopper. The light scattering setup was calibrated against a known, particlefree flow composed of argon. Soot particle size, number density, and volume fraction calculations were carried out by assuming monodisperse particles having a complex refractive index of $1.54-0.58 \mathrm{i}[16,17]$.

Temperature measurements were obtained with a silicon oxide-coated $0.15 \mathrm{~mm} \mathrm{Pt}-13 \% \mathrm{Rh} / \mathrm{Pt}$ thermocouple (Omega Engineering Inc.). After each measurement, thermocouple was withdrawn from the flame and the accumulated soot was burnt off using a small propane torch. The temperature profiles reported in this study correspond to direct thermocouple readings and were not corrected for radiation losses.

Temperature and soot profiles were obtained by moving the entire burner assembly vertically up or down. The positional accuracy associated with these measurements was estimated to be $\pm 0.2 \mathrm{~mm}$.

\section{Artificial neural networks}

The development of ANNs began approximately 50 years ago, inspired by a desire to understand the human brain and emulate its functioning. Within the last decade, it has experienced a huge resurgence due to the development of more sophisticated algorithms and the emergence of powerful computer tools. Mathematically, an ANN is often viewed as a universal approximator. The ability to identify a relationship from given patterns make it possible for ANNs to solve large-scale complex problems such as pattern recognition, non-linear modeling, classification, association, and control. Consequently, ANNs have found applications in such diverse areas as neurophysiology, physics, environmental engineering, electrical engineering,

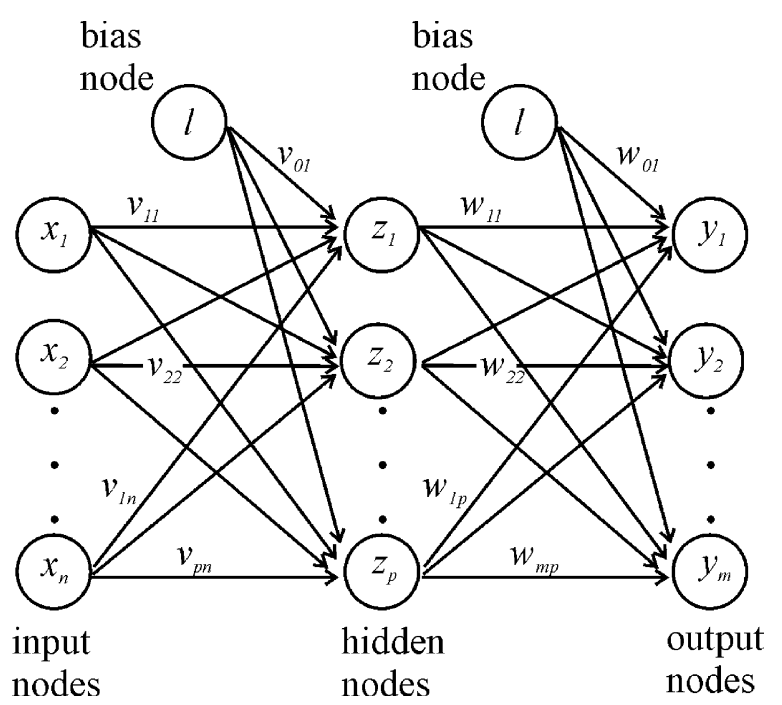

Fig. 2. Architecture of a three-layer feed-forward type neural network.

chemical engineering, computer science, robotics, image processing, financing, and others.

In this study, the common three-layer feed-forward type of ANN, as shown in Fig. 2, was considered for the prediction of soot properties. In a feed-forward network, the input quantities are fed into input layer neurons, which in turn pass them on to the hidden layer neurons after multiplying by a weight. A hidden layer neuron adds up the weighted input received from each input neuron, associates it with a bias, and then passes the result on through a non-linear transfer function (Fig. 3). The output neurons do the same operation as that of a hidden neuron.

Before its application to any problem, the network is first trained, whereby the target output at each output neuron is compared with the network output and the difference or error is minimized by adjusting the weights and biases through some training algorithm. Training in ANNs consists of three elements: (1) weights between neurons that define the relative importance of the inputs, (2) a transfer function that controls the generation of the output from a neuron, (3) learning laws that describe how the adjustments of

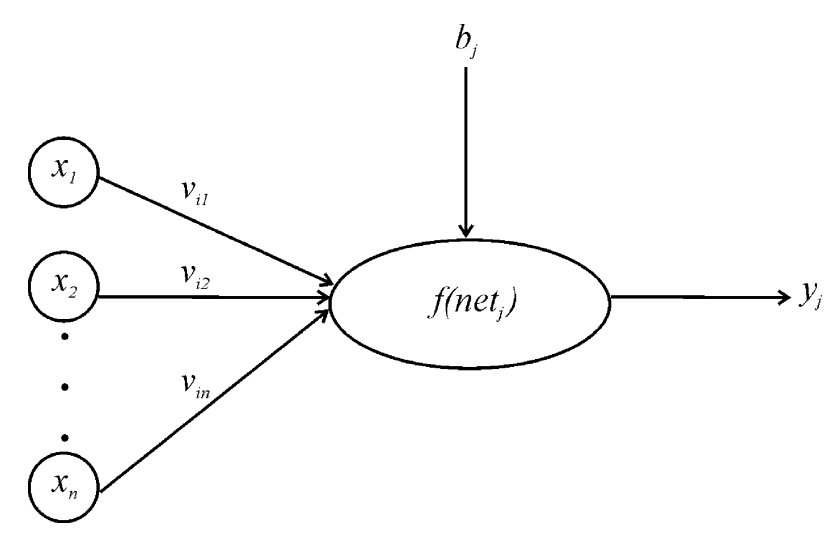

Fig. 3. Structure of a hidden layer neuron. 
the weights are made during training. During training, a neuron receives inputs from a previous layer, weights each input with a prearranged value, and combines these weighted inputs. The combination of the weighted inputs is represented as

net $_{j}=\sum x_{i} v_{i j}$

where net ${ }_{j}$ is the summation of the weighted input for the $j$ th neuron; $x_{i}$ the input from the $i$ th neuron to the $j$ th neuron; and $v_{i j}$ the weight from the $i$ th neuron in the previous layer to the $j$ th neuron in the current layer.

The net ${ }_{j}$ is passed through a transfer function to determine the level of activation. If the activation of a neuron is strong enough, it produces an output that is sent as an input to other neurons in the successive layer. In this study, sigmoid function was employed as an activation function in the training of the network. The sigmoid function is a bounded, monotonic, non-decreasing function that provides a graded, non-linear response. This function enables a network to map any non-linear process. One of the main reasons that the sigmoid function was employed is because of its simplicity of its derivative that is required during the training process [18]. The sigmoid function is expressed as:

$f\left(\right.$ net $\left._{j}\right)=\frac{1}{1+\mathrm{e}^{- \text {net }_{j}}}$

The learning of ANNs was accomplished by a backpropagation algorithm. Back-propagation is the most commonly used supervised training algorithm in the multi-layered feed-forward networks. In back-propagation networks, information is processed in the forward direction from the input layer to the hidden layer and then to the output layer (Figs. 2 and 3). The objective of a backpropagation network is, by minimizing a predetermined error function, to find the optimal weights which would generate an output vector $\mathbf{Y}=\left(y_{1}, y_{2}, \ldots, y_{p}\right)$ as close as possible to target values of output vector $\mathbf{T}=\left(t_{1}, t_{2}, \ldots, t_{p}\right)$ with a selected accuracy. A predetermined error function has the following form [18]

$E=\sum_{P} \sum_{p}\left(y_{i}-t_{i}\right)^{2}$

where $y_{i}$ is the component of an ANN output vector $\mathbf{Y} ; t_{i}$ the component of a target output vector $\mathbf{T} ; p$ the number of output neurons; and $P$ the number of training patterns.

The least square error method, along with a generalized delta rule, was used to optimize the network weights. The gradient descent method, along with the chain rule of derivatives, was employed to modify network weights as

$v_{i j}^{\text {new }}=v_{i j}^{\text {old }}-\delta \frac{\partial E}{\partial v_{i j}}$

where $\delta$ is the learning rate which is used to increase the chance of avoiding the training process being trapped in local minima instead of global minima.

\section{Results and discussion}

The pre-combustion compositions of the 12 flames studied are given in Table 1. Before presenting results, a number of issues related to these conditions must be stated. First, the equivalence ratios were determined to provide stable sooting flames after a number of different possibilities were explored. At lower equivalence ratios, flames did not produce as much soot. Flames above an equivalence ratio of 2.6 were too unstable. Second, in all the flames of methane, ethane, propane, and butane, the volumetric flow rates of these gases were maintained constant at 1.88, 1.71, 1.20, and $1.07 \mathrm{l} / \mathrm{min}$, respectively, while the flow rates of oxygen and argon were varied. Third, the argon dilution was kept at $45 \%$ in all flames. This allowed for a better control of the flame temperatures.

The temperature profiles for the flames studied are presented in Fig. 4. The data points represent experimental results and solid lines represent trends in all the figures given in this study. For each fuel, lower equivalence ratio flames were positioned closest to the burner surface because of their higher burning velocities. In contrast, the equivalence ratio of 2.6 flames had lowest burning velocity and were located farthest from the burner. It is also important to note that the differences in peak temperatures were about $5 \mathrm{~K}$ for methane flames, $15 \mathrm{~K}$ for ethane flames, $20 \mathrm{~K}$ for propane flames, and $50 \mathrm{~K}$ for butane flames. In sooting flames, one of the major problems in temperature measurement is the coating of the thermocouple junction by soot particles. Although the accumulated soot on thermocouple bead was burnt off after each measurement, soot deposition was inevitable at higher distances above the burner surface. This deposition process increased the radiative heat loses from the thermocouple bead and resulted in lower

Table 1

Experimental conditions used in the study of soot formation in premixed hydrocarbon flames

\begin{tabular}{lrrrr}
\hline & Methane & Ethane & Propane & Butane \\
\hline Equivalence ratio: 2.4 & & & & \\
Fuel composition (mole\%) & 29.98 & 22.38 & 17.83 & 14.82 \\
Oxygen composition (mole\%) & 25.04 & 32.59 & 37.15 & 40.17 \\
Ar composition (mole\%) & 44.98 & 45.03 & 45.02 & 45.01 \\
Total flow rate (lpm) & 6.27 & 7.64 & 6.73 & 7.22 \\
& & & & \\
Equivalence ratio: 2.5 & & & & \\
Fuel composition (mole\%) & 30.57 & 22.92 & 18.32 & 15.29 \\
Oxygen composition (mole\%) & 24.39 & 32.04 & 36.64 & 39.71 \\
Ar composition (mole\%) & 45.04 & 45.04 & 45.04 & 45.00 \\
Total flow rate (lpm) & 6.15 & 7.46 & 6.55 & 7.00 \\
& & & & \\
Equivalence ratio: 2.6 & & & & \\
Fuel composition (mole\%) & 31.07 & 23.46 & 18.81 & 15.71 \\
Oxygen composition (mole\%) & 23.97 & 31.55 & 36.21 & 39.35 \\
Ar composition (mole\%) & 44.96 & 44.99 & 44.98 & 44.93 \\
Total flow rate (lpm) & 6.05 & 7.29 & 6.38 & 6.81 \\
\hline
\end{tabular}

Calculated at $298 \mathrm{~K}$ and $1 \mathrm{~atm}$. 


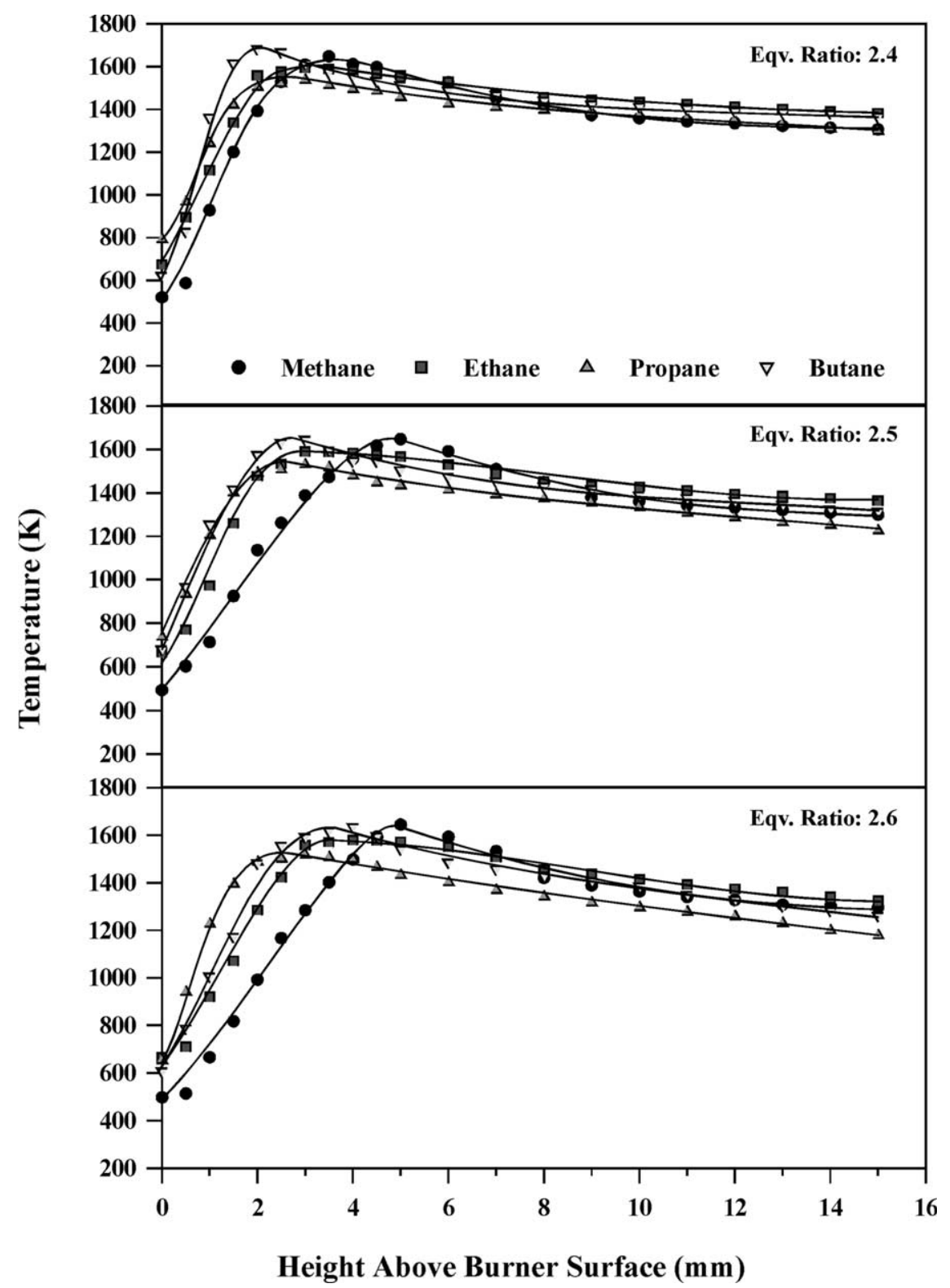

Fig. 4. Flame temperatures

temperature readings. The previous studies have shown that the temperature recorded by a thermocouple that was cleaned between measurements were higher than those recorded by an uncleaned thermocouple by as much as $50{ }^{\circ} \mathrm{C}$ in post flame regions [19].

Soot properties were calculated by assuming monodisperse soot particles that were smaller than the wavelength of the light used to comply with the Rayleigh scattering approximation. However, non-spherical and polydisperse soot occurs within the flame due to the agglomeration of primary soot particles. The Rayleigh approximation has been demonstrated to have negligible effect on the determination of the soot volume fraction and hold to within a factor of three for the particle diameters $\left(d_{\mathrm{p}}\right)$. However, because of $d_{\mathrm{p}}^{-3}$ dependence of particle number density, Rayleigh analysis causes a significant uncertainty in number density estimation [20]. Soot volume fractions, particle diameters, and number densities are presented in Figs. 5-7. The rate-controlling step to soot emission is the rate of formation of the first aromatic ring [21]. In a flame, the hydrocarbon fuel is decomposed into small hydrocarbon radicals from which mostly acetylene is formed. Frenklach and Wang [22] proposed that the formation of first aromatic ring in flames of non-aromatic fuels usually begins with vinyl addition to acetylene. Vinylacetylene is formed at high temperatures, followed by acetylene addition to $n-\mathrm{C}_{4} \mathrm{H}_{3}$ radical formed by the $\mathrm{H}$-abstraction from the vinylacetylene. The benzene can also be formed by combination of propargyl radicals producing benzene or phenyl [23]. Starting from an initial aromatic structure, the larger 


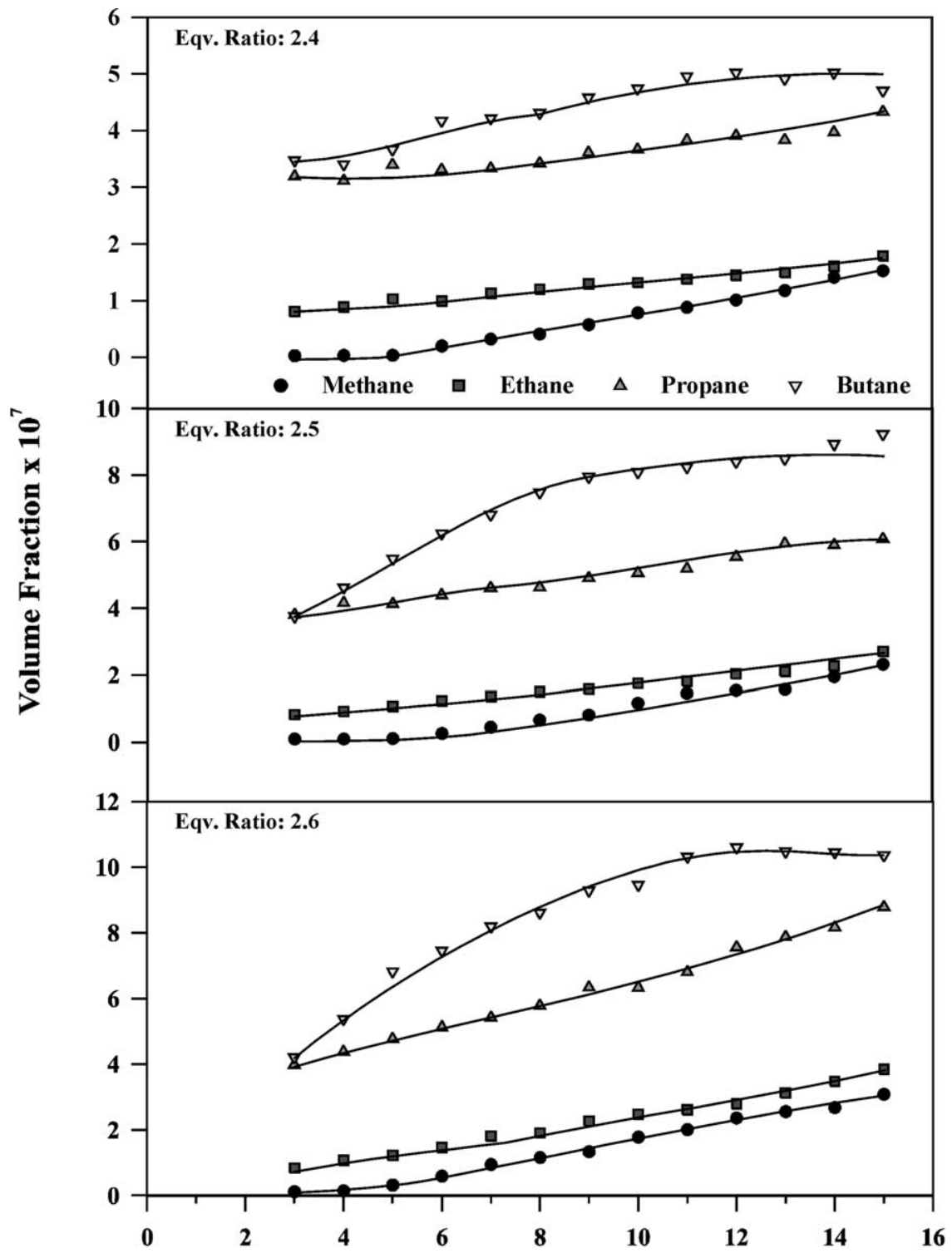

Height Above Burner Surface (mm)

Fig. 5. Soot volume fractions.

aromatics can be built by the addition of non-aromatics such as $\mathrm{C}_{2} \mathrm{H}_{2}$ and $\mathrm{C}_{4} \mathrm{H}_{5}$. The addition of aromatic radicals to nonaromatics can also lead to condensed ring compounds [24]. The aromatic structures then reach a large enough size to turn into particle nuclei. Small soot particles are grown either by addition from the gas phase or by coalescence. The formation of larger soot particles by coalescing small particles is known as coagulation.

As can be seen from Fig. 5, for each fuel, the soot volume fraction or amount of soot was initially only small fraction of the final amount. As soot volume fraction increases, the particles also grow in size (Fig. 6). In contrast, the particle number density decreases by coagulation and gradually levels off (Fig. 7). This process leads to an increase in particle size and a simultaneous increase in soot volume fraction. The soot volume fractions reached the amount of $3.08 \times 10^{-7}, 3.84 \times 10^{-7}, 8.78 \times 10^{-7}, 10.36 \times 10^{-7}$ in methane, ethane, propane, and butane flames, respectively, at equivalence ratio of 2.6. The lower equivalence ratio flames produced less soot due to the flame temperature consideration (Fig. 5). The temperature affects the two competing processes occurring in premixed sooting flames: the pyrolysis rate of the fuel intermediate leading to the precursors and the rate of oxidative (OH radical) attack on these precursors [21]. Both rates increase with temperature, but the oxidative attack rate increases faster.

Methane flames showed larger particle diameters at higher distances above the burner surface and propane, 


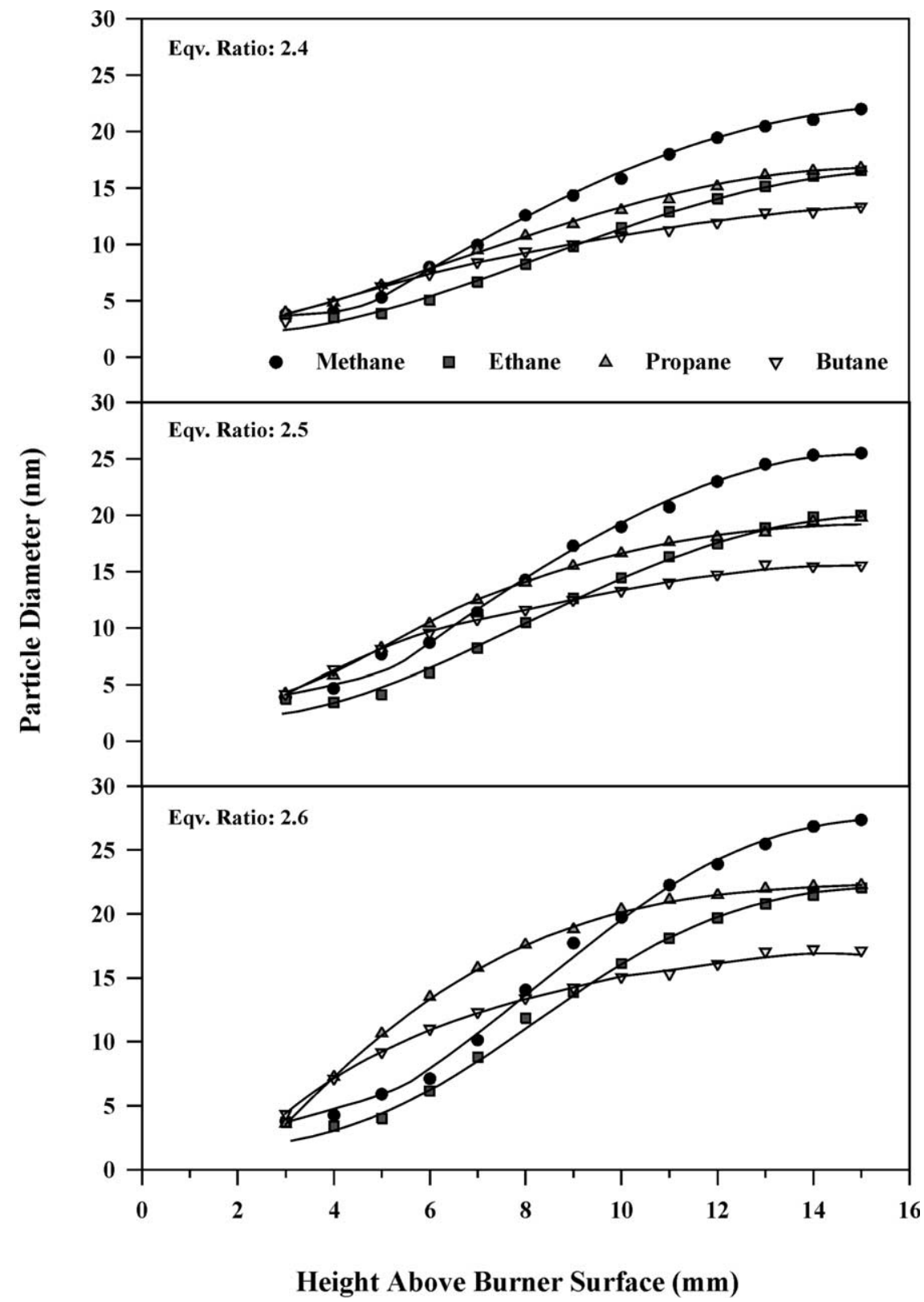

Fig. 6. Soot particle diameters.

ethane, and butane flames came after the methane flames, respectively (Fig. 6). The maximum soot particle diameters were about 22, 25 and $27 \mathrm{~nm}$ in methane flames at equivalence ratios of 2.4, 2.5, and 2.6, respectively. Senkan and Castaldi [25] reported an increased production of PAH while the acetylene and soot levels were less in the laminar, premixed methane flame compared to ethane under similar conditions. These interesting experimental results were supported by a recent study of Roesler et al. [26] in an isothermal laminar flow reactor at atmospheric pressure. Roesler et al. [26] showed that methane contributes significantly in determining the growth rate of aromatic species and soot in fuel-rich premixed combustion. Methane increases the methyl radical concentration and the presence of methyl radical promotes the formation of hydrocarbon species containing an odd-number of carbon atoms, which would then accelerate benzene and naphthalene formation $[25,26]$. Although we have measured larger particle diameters for methane flames at higher distances above the burner surface, soot volume fraction steadily increased with increasing carbon number in the fuel and increasing equivalence ratio for each fuel (Fig. 5). Likewise, soot number density also increased with increasing carbon number in the fuel (Fig. 7).

ANNs having seven input neurons and one output neuron were used to model the soot properties. After several trial and error runs for training and testing, it was found that the utilization of two neural networks instead of one with two 


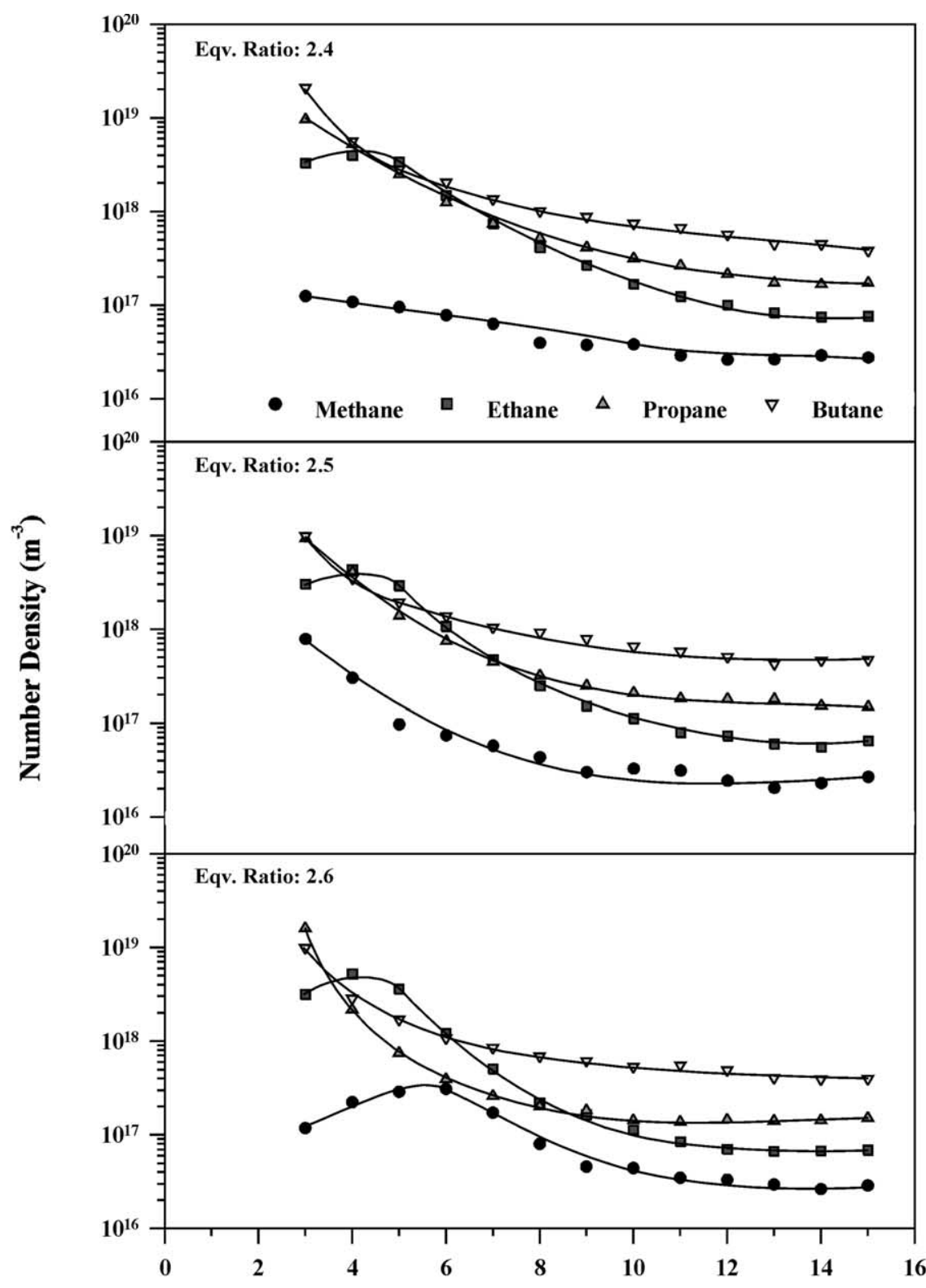

Height Above Burner Surface (mm)

Fig. 7. Soot number densities.

outputs provides better predictions. The input variables used in the models were distance from the burner surface, flame temperature, equivalence ratio, $\mathrm{C} / \mathrm{H}$ ratio, fuel flow rate, oxygen flow rate, and argon flow rate. Soot particle diameters and volume fractions were used as the outputs for the neural networks. The input and output parameters are given in Table 2 with their minimum and maximum values. The number of hidden neurons for the network was five for the particle diameters and was seven for the volume fractions. Due to the greater uncertainty in the determination of number density that has been mentioned before and a large minimummaximum range (i.e. $2 \times 10^{16}-2 \times 10^{19}$ ) of this parameter,
Table 2

Input and output parameters of neural networks

\begin{tabular}{lll}
\hline Parameter & Minimum & Maximum \\
\hline Distance from the burner surface $(\mathrm{mm})$ & 3 & 15 \\
Temperature $(\mathrm{K})$ & 1167 & 1647 \\
Equivalence ratio & 2.4 & 2.6 \\
C/H ratio & 0.25 & 0.4 \\
Fuel flow rate (lpm) & 1.07 & 1.88 \\
Oxygen flow rate (lpm) & 1.45 & 2.90 \\
Argon flow rate $(\mathrm{lpm})$ & 2.72 & 3.44 \\
Soot particle diameter $(\mathrm{nm})$ & 3.17 & 27.35 \\
Volume fraction $\times 10^{7}$ & 0.03 & 10.60 \\
\end{tabular}




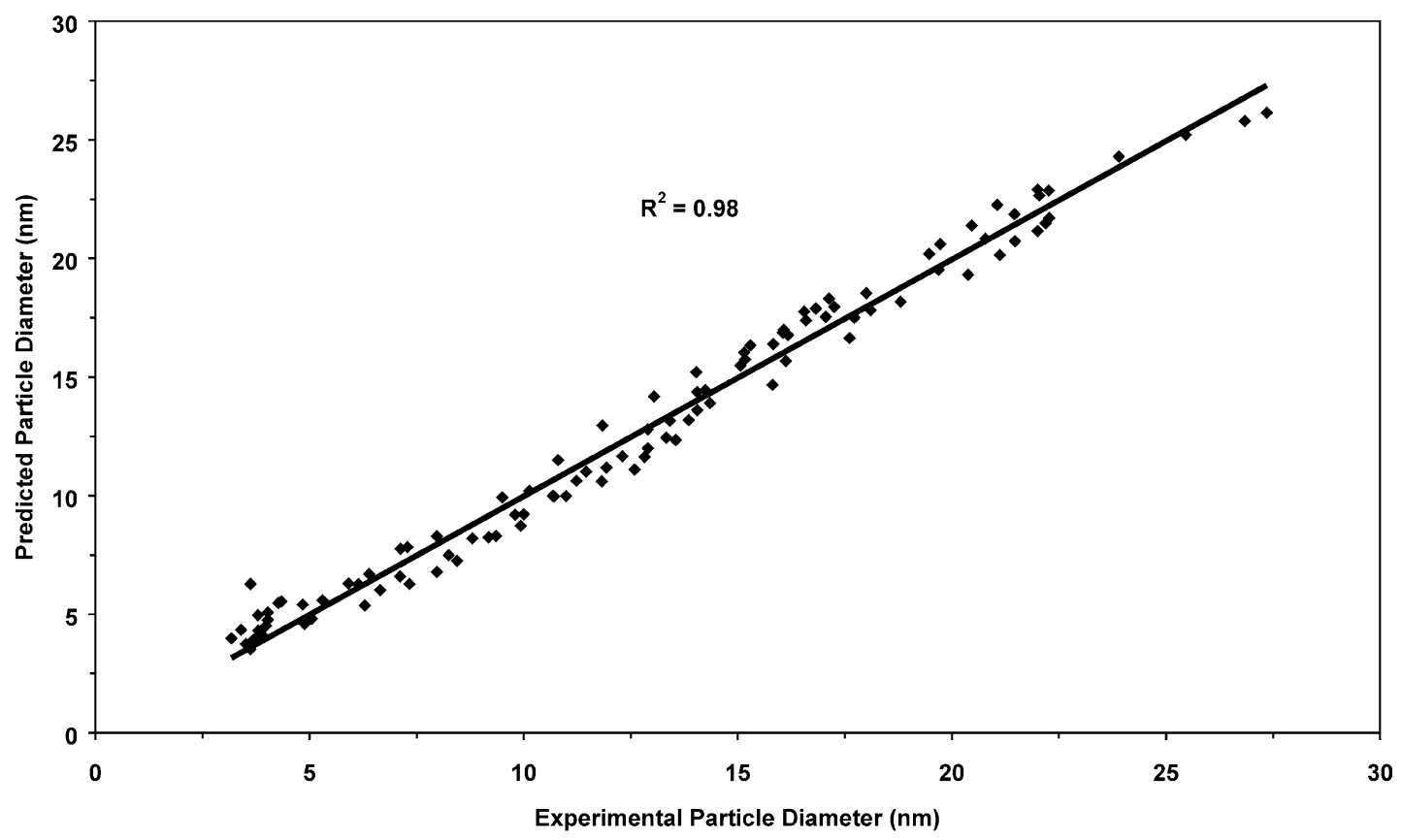

(a)

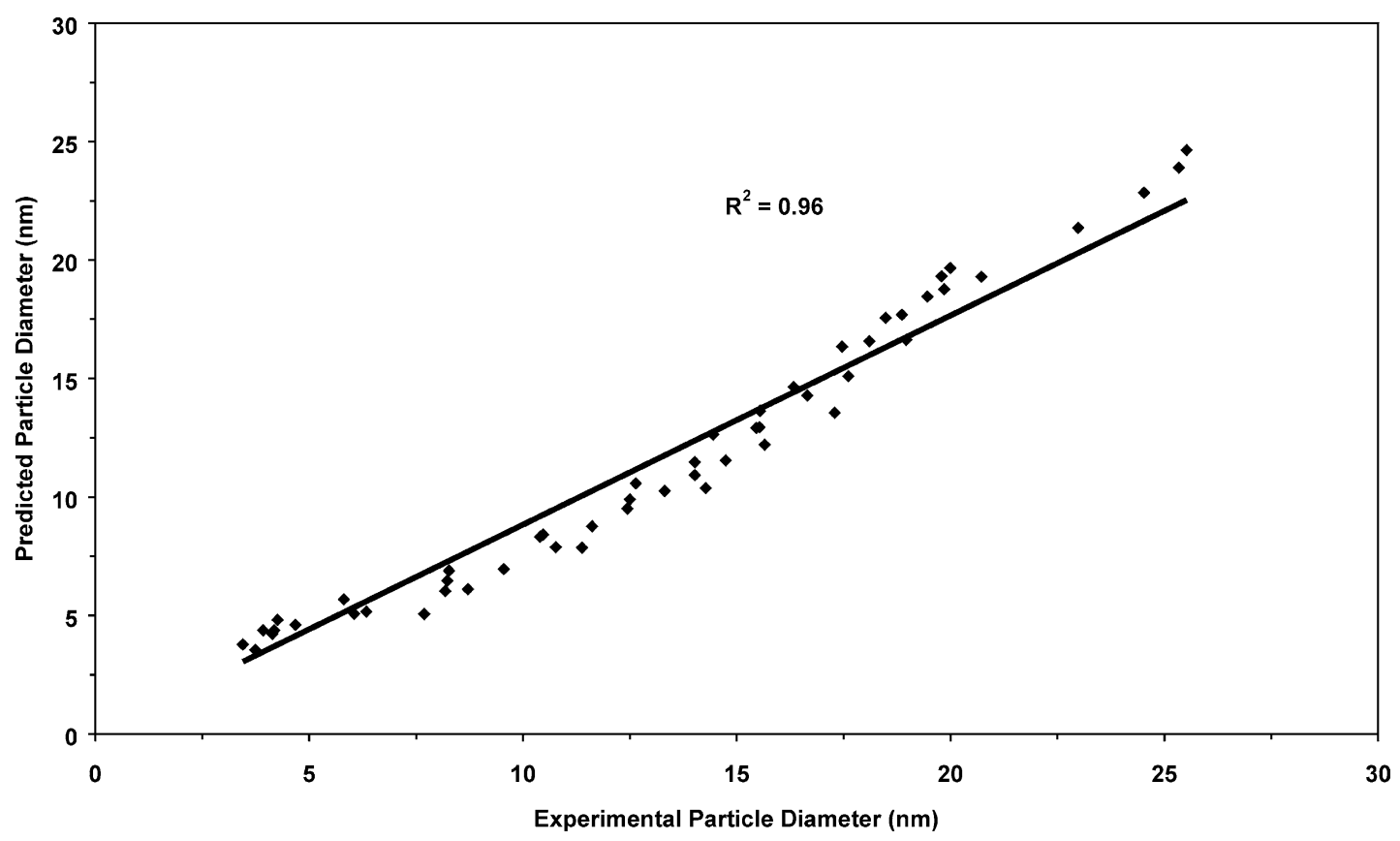

(b)

Fig. 8. Experimental and ANN predicted values of particle diameters for Case I (a) training set, (b) testing set.

network was not trained and tested with sufficient accuracy. Therefore, the modeling results for only particle diameters and volume fractions were given here.

The performance of the neural networks was investigated for the following two cases:

(I) The data for the methane, ethane, propane and butane flames at equivalence ratios of 2.4 and 2.6 were used as inputs to predict the particle diameters and volume fractions of the same flames at an equivalence ratio of 2.5.

(II) Methane, ethane, and propane flame data at equivalence ratios of $2.4,2.5$, and 2.6 were used to predict the particle diameters and volume fractions of butane flames at the same equivalence ratios. 


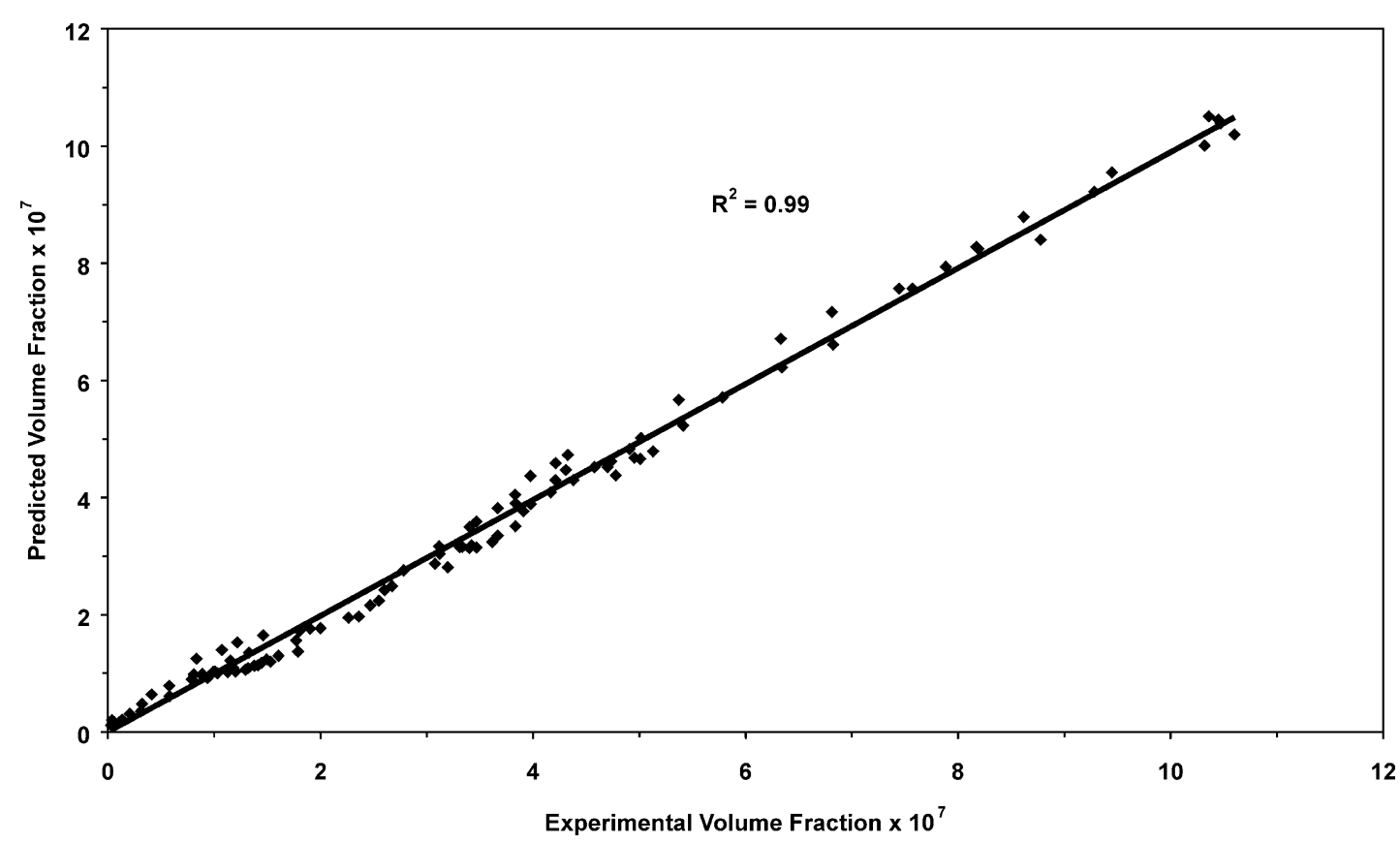

(a)

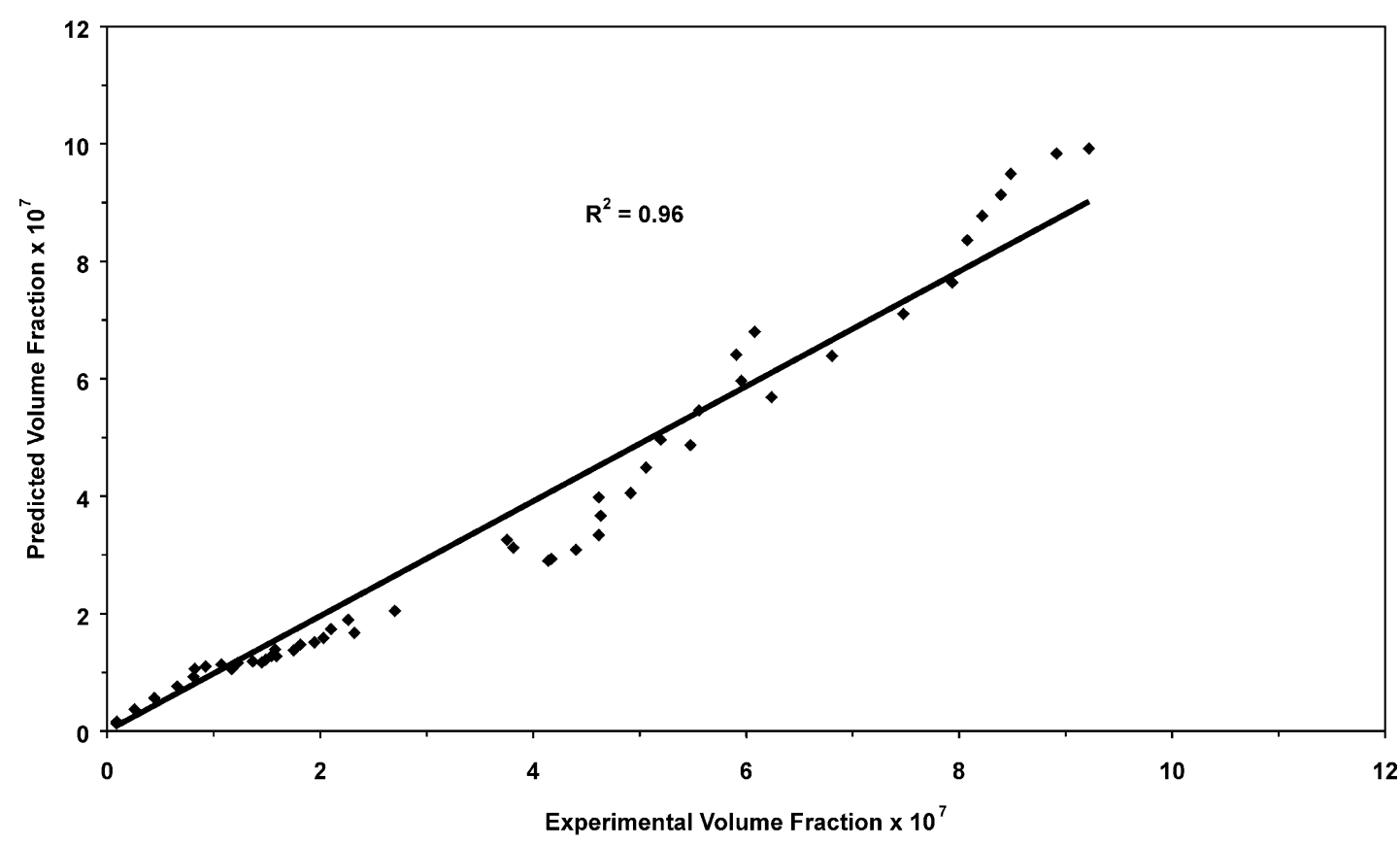

(b)

Fig. 9. Experimental and ANN predicted values of volume fractions for Case I (a) training set, (b) testing set.

One hundred and fifty six data sets were divided into two groups for training and testing, each containing 104 and 52 sets for Case I and 117 and 39 sets for Case II, respectively.

The predicted and experimental values of particle diameters and volume fractions are shown in Figs. 8 and 9 for Case I. As can be seen from these figures, the comparison of the predicted values and experimental measurements shows good agreement. The correlation coefficients $\left(R^{2}\right)$ of the particle diameters and volume fractions were 0.98 and 0.99 for the training sets and 0.96 and 0.96 for the testing sets, respectively. The average absolute errors were $14.58 \%$ for the particle diameters and $17.36 \%$ for the volume fractions in testing.

$R^{2}$ values of the particle diameters and volume fractions in Case II were 0.99 and 0.99 for the training sets and 0.92 and 0.86 for the testing sets, respectively (Figs. 10 and 11). 
The average absolute errors in testing for particle diameters $(18.90 \%)$ and volume fractions $(27.15 \%)$ were larger than those in Case I. This is because the most of the predicted butane data was outside the data range used in the training.

The effects of each input variable on soot particle diameter and volume fraction were also investigated. The analysis results indicated that the effects of flow rates of fuel, oxygen and argon on particle diameter and volume fraction were insignificant, and the related results, for the sake of brevity, are not presented herein. On the other hand, the effects of distance from the burner surface, temperature, equivalence ratio and $\mathrm{C} / \mathrm{H}$ ratio were significant (Figs. 12-15). As can be seen from Fig. 12, soot particle diameter and volume fraction increased with increase in

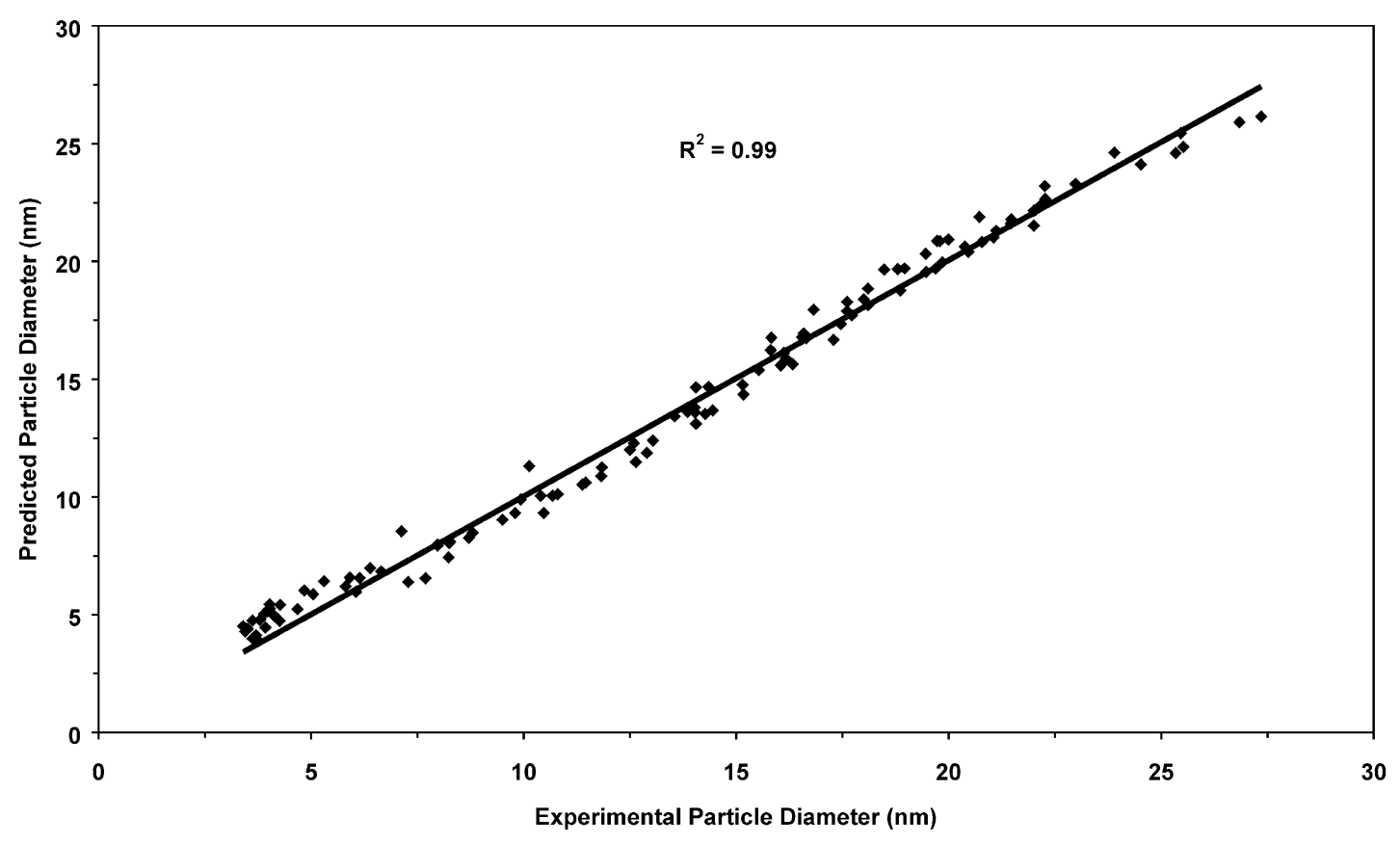

(a)

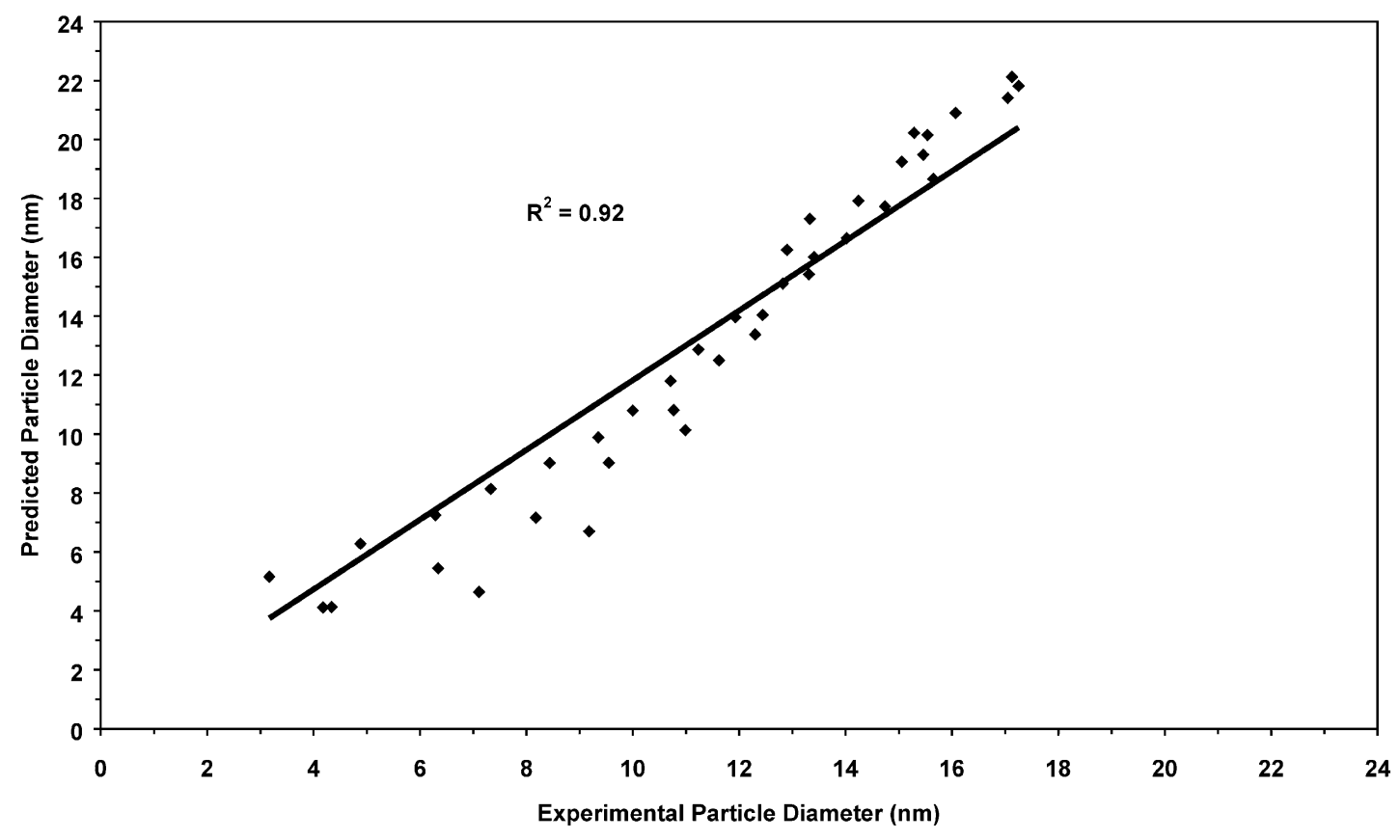

(b)

Fig. 10. Experimental and ANN predicted values of particle diameters for Case II (a) training set, (b) testing set. 
distance from the burner surface. Due to the stronger temperature dependence of the rate of oxidative attack on soot precursors in premixed sooting flames, as we discussed before, both particle diameter and volume fraction decreased with increasing temperature (Fig. 13). Soot volume fraction and particle diameter increased with increasing equivalence ratio (Fig. 14). However, the equivalence ratio dependence was not strong for the case of particle diameter. The change in $\mathrm{C} / \mathrm{H}$ ratio affected particle diameter and volume fraction differently (Fig. 15). The particle diameter decreased with increasing $\mathrm{C} / \mathrm{H}$ ratio. However, the volume fraction exhibited increasing trend. These modeling results agree with our experimental measurements.

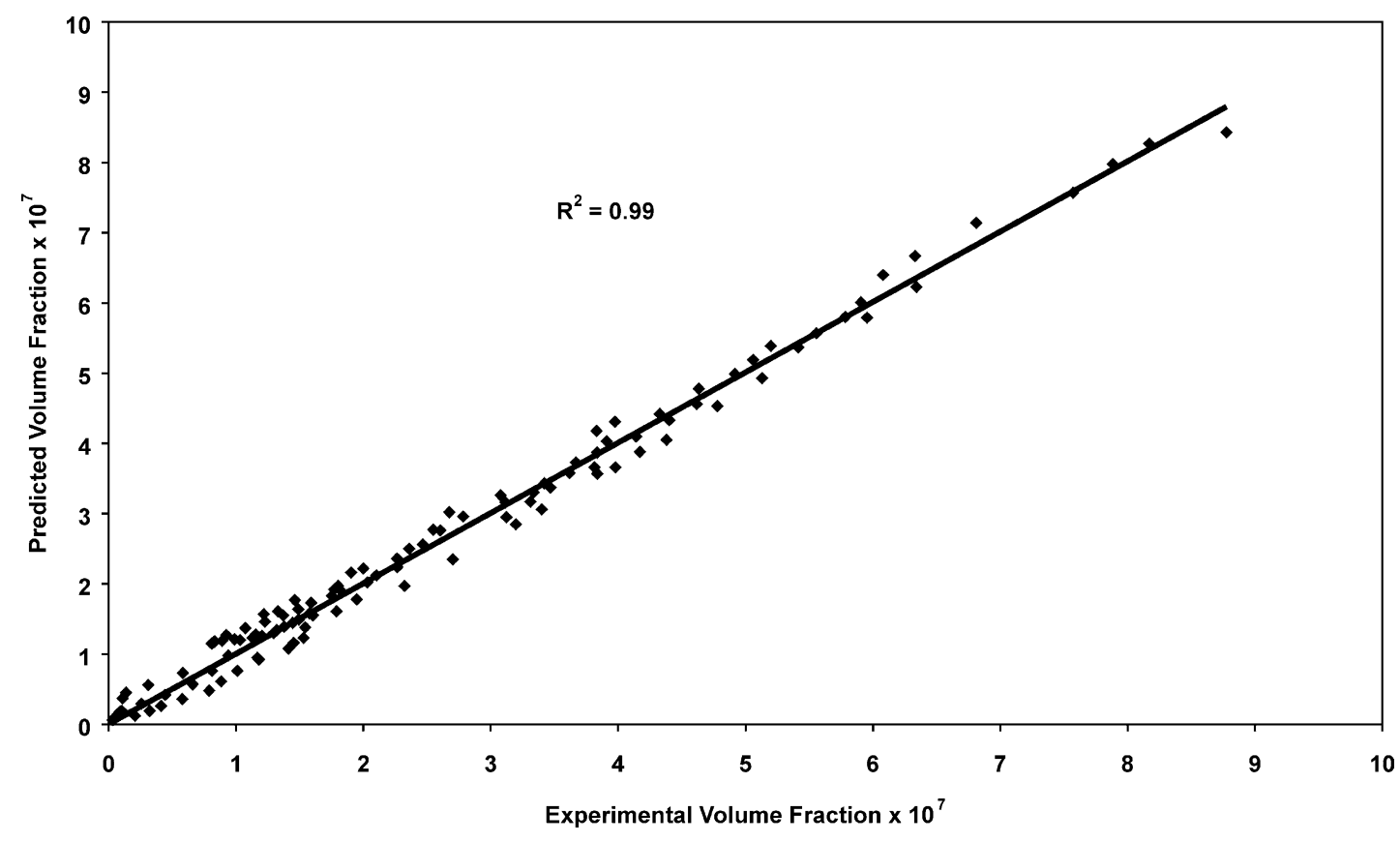

(a)

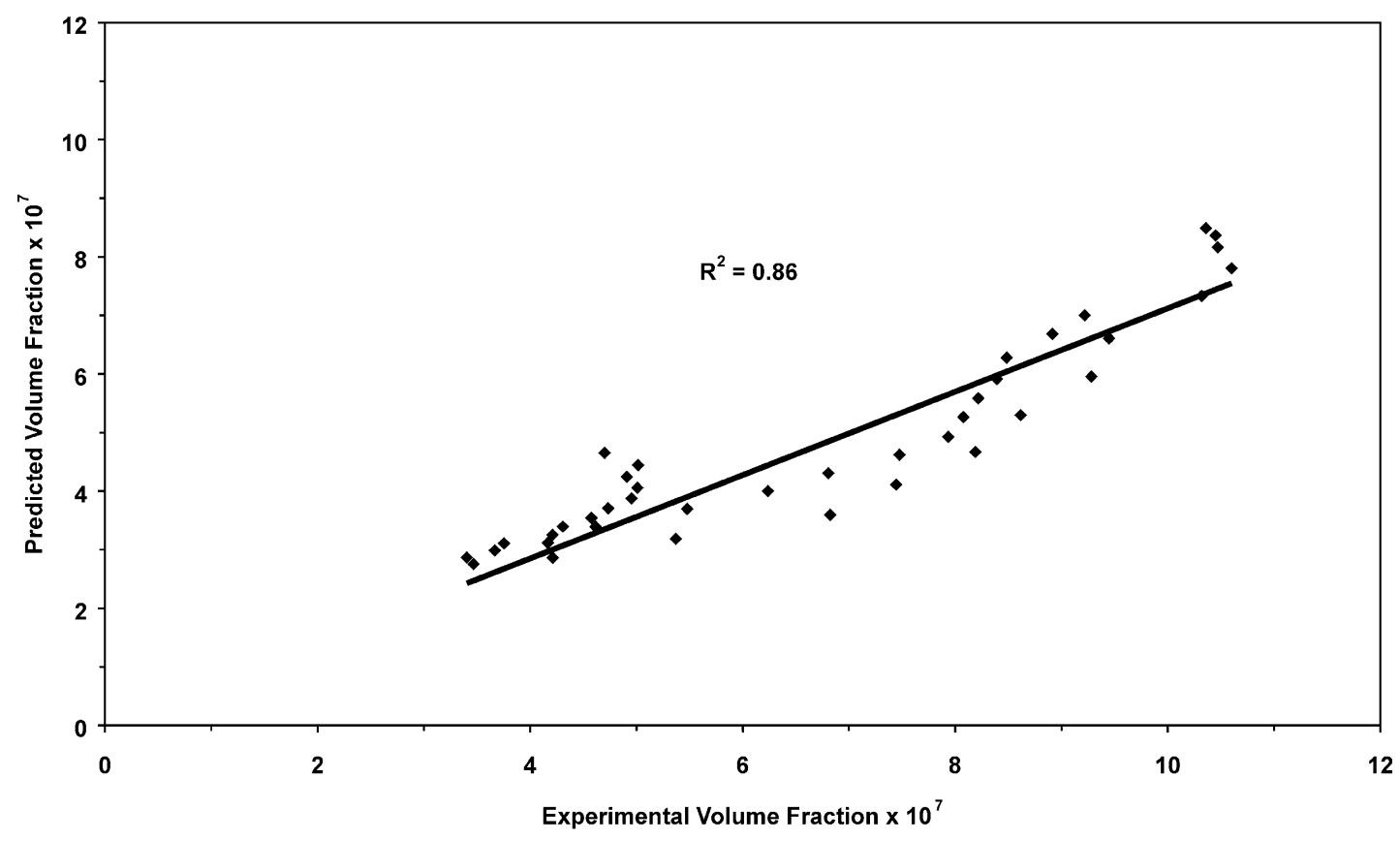

(b)

Fig. 11. Experimental and ANN predicted values of volume fractions for Case II (a) training set, (b) testing set. 


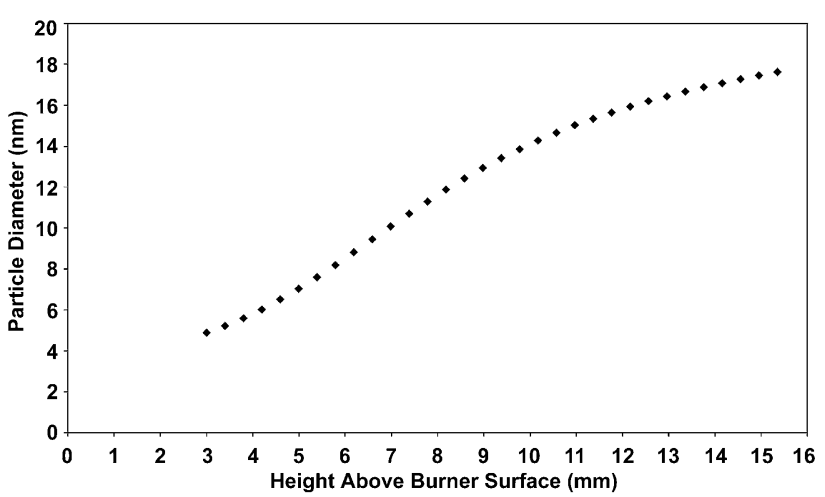

(a)

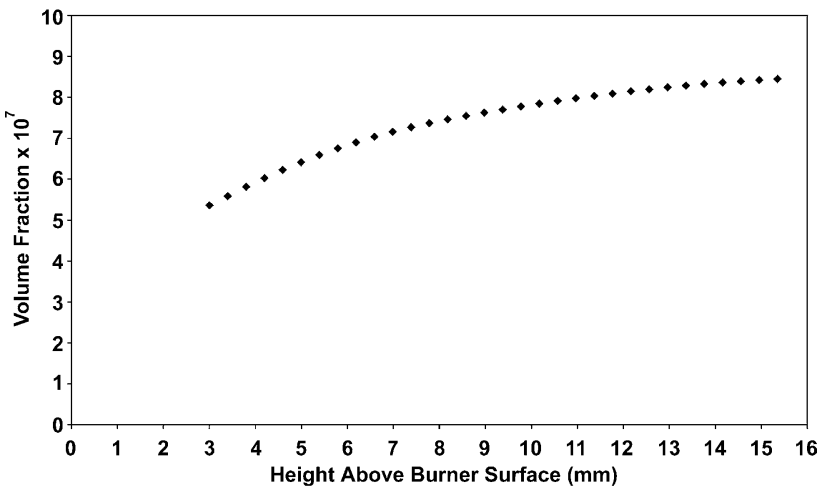

(b)

Fig. 12. Effect of distance from burner surface on (a) particle diameter and (b) volume fraction.

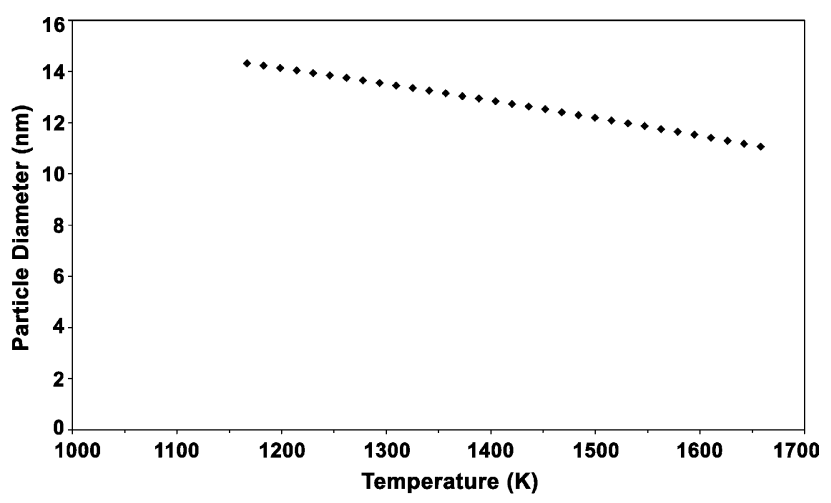

(a)

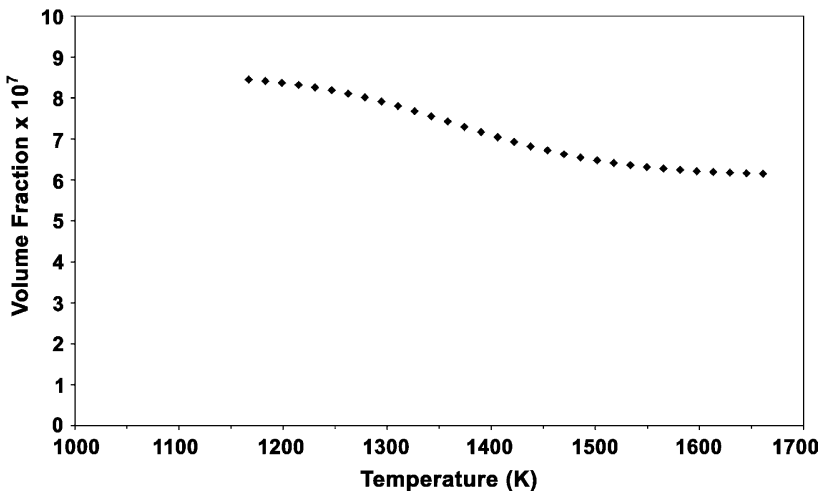

(b)

Fig. 13. Effect of temperature on (a) particle diameter and (b) volume fraction.

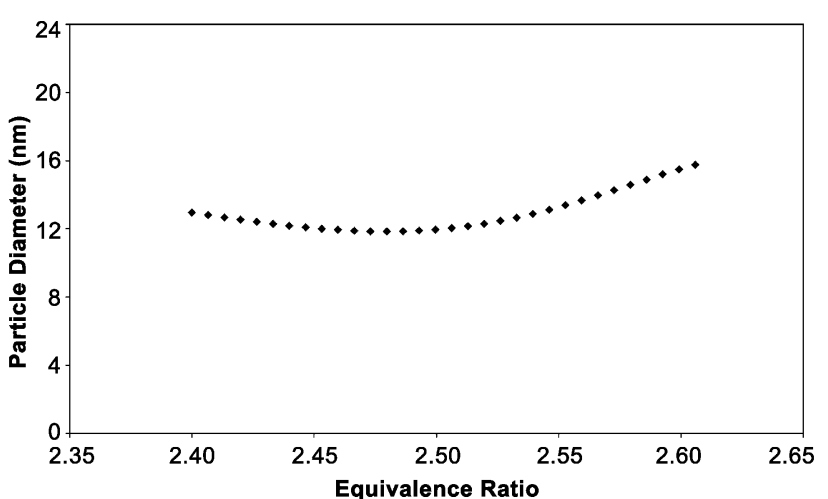

(a)

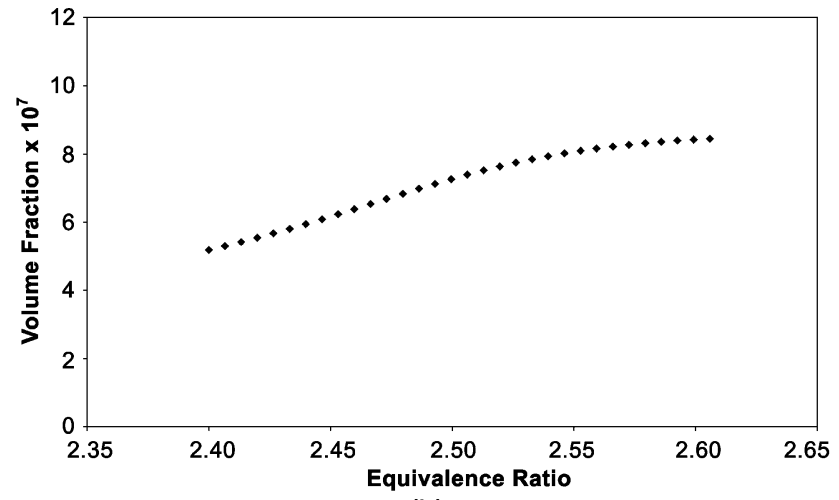

(b)

Fig. 14. Effect of equivalence ratio on (a) particle diameter and (b) volume fraction.

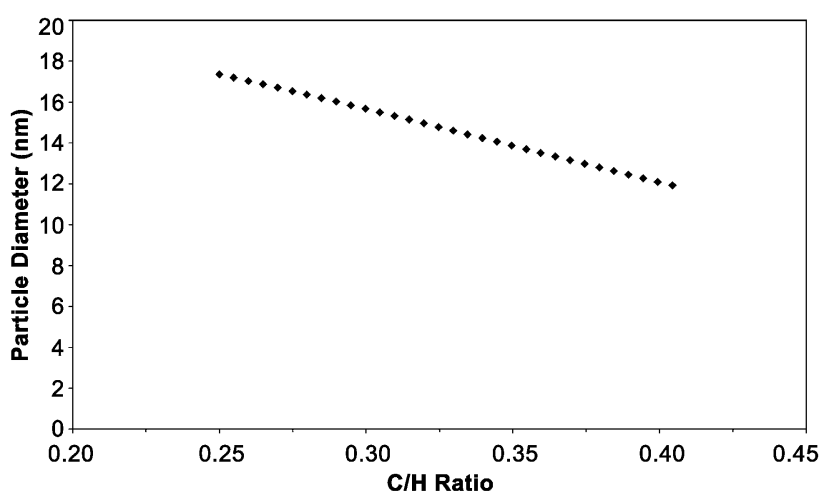

(a)

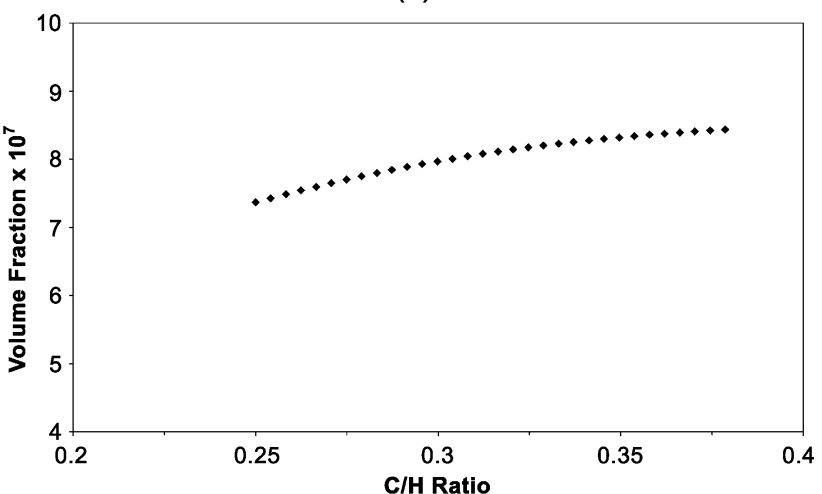

(b)

Fig. 15. Effect of $\mathrm{C} / \mathrm{H}$ ratio on (a) particle diameter and (b) volume fraction. 


\section{Conclusion}

In conclusion, our experimental results revealed that the soot properties were influenced by the fuel type and equivalence ratio. Increase in equivalence ratio increased the amount of soot formed for each fuel. In addition, butane flame produced the largest amount of soot among the hydrocarbon fuels studied. However, the particle sizes in methane flames were consistently larger than those measured in other flames at higher distances above the burner surface. In addition, an ANN approach was successfully applied to predict soot particle diameters and volume fractions for two cases. The comparison of the ANN predictions with the experimental values was satisfactory. Furthermore, the sensitivity analysis results were also consistent with the experimental observations. Hence, the ANNs could be a useful tool in pollutant formation studies.

\section{References}

[1] Haynes BS. Soot and hydrocarbons in combustion. In: Bartok W, Sarofim AF, editors. Fossil fuel combustion. New York: Wiley; 1991.

[2] Barfknecht TR. Prog Energy Combust Sci 1983;9:199.

[3] Wagner HGG. Proc Combust Inst 1978;17:3.

[4] Harris SJ, Weiner AM. Ann Rev Phys Chem 1985;36:31.

[5] Violi A, D’Anna A, D’Alessio A. Chem Engng Sci 1999;54:3433.
[6] Richter H, Howard JB. Prog Energy Combust Sci 2000;26:565.

[7] Baumgartner L, Hesse D, Jander H, Wagner HGG. Proc Combust Inst 1984;20:959.

[8] Melton TR, Vincitore AM, Senkan SM. Proc Combust Inst 1998;27: 1631.

[9] Melton TR, Inal F, Senkan SM. Combust Flame 2001;121:671.

[10] Senkan SM. Adv Chem Engng 1992;18:95.

[11] Frenklach M, Clary DW, Gardiner WC, Stein SE. Proc Combust Inst 1986;21:1067.

[12] McEnally CS, Koylu UO, Pfefferle LD, Rosner DE. Combust Flame 1997;109:701

[13] Hao Z, Kefa C, Jianbo M. Fuel 2001;80:2163.

[14] Duran A, A de L, Carmona M, Ballesteros R. Chemosphere 2001;44: 921.

[15] A de L, Duran A, Carmona R, Lapuerta M. Fuel 2001;80:539.

[16] Flower WL. SPIE 1986;644:28.

[17] Faeth GM, Koylu UO. Combust Sci Technol 1995;108:207-29.

[18] ASCE Task Committee, J Hydrol Engng, ASCE 2000;5(2):115.

[19] Castaldi MJ, Vincitore AM, Senkan SM. Combust Sci Technol 1995; 107:1.

[20] Koylu UO. Combust Flame 1996;109:488.

[21] Glassman I. Proc Combust Inst 1988;22:295

[22] Frenklach M, Wang H. Detailed mechanism and modeling of soot particle formation. In: Bockhorn $\mathrm{H}$, editor. Soot formation in combustion. Berlin: Springer; 1994.

[23] Miller JA, Melius CF. Combust Flame 1992;91:21.

[24] Bittner JD, Howard JB. Proc Combust Inst 1981;18:1105.

[25] Senkan SM, Castaldi M. Combust Flame 1996;107:141.

[26] Roesler JF, Auphan de Tessan M, Montagne X. Chemosphere 2001; 42:823. 